$12-2013$

Recession Depression: Mental Health Effects of the 2008 Stock Market Crash

Melissa McInerney

Jennifer M. Mellor

Lauren H. Nicholas

Follow this and additional works at: https://scholarworks.wm.edu/aspubs

Part of the Economics Commons 


\title{
Recession Depression: Mental Health Effects of the 2008 Stock Market Crash*
}

\author{
Melissa McInerneya ${ }^{a}$ Jennifer M. Mellor ${ }^{a}$, and Lauren Hersch Nicholas ${ }^{b}$ \\ Melissa Mclnerney: mpmcinerney@wm.edu; Jennifer M. Mellor: jmmell@wm.edu; Lauren Hersch Nicholas: \\ Inichola@jhsph.edu \\ aThe College of William \& Mary, Department of Economics, P.O. Box 8795, Williamsburg, VA \\ 23187-8795, USA \\ bJohns Hopkins Bloomberg School of Public Health, Department of Health Policy \& Management, \\ 624 North Broadway, Baltimore, MD 21205
}

\begin{abstract}
Do sudden, large wealth losses affect mental health? We use exogenous variation in the interview dates of the 2008 Health and Retirement Study to assess the impact of large wealth losses on mental health among older U.S. adults. We compare cross-wave changes in wealth and mental health for respondents interviewed before and after the October 2008 stock market crash. We find that the crash reduced wealth and increased feelings of depression and use of antidepressant drugs, and that these effects were largest among respondents with high levels of stock holdings prior to the crash. These results suggest that sudden wealth losses cause immediate declines in subjective measures of mental health. However, we find no evidence that wealth losses lead to increases in clinically-validated measures of depressive symptoms or indicators of depression.
\end{abstract}

\section{Keywords}

Mental health; depression; health status; wealth; income

\section{Introduction}

Do sudden, large wealth losses affect mental health? Despite a large literature on the relationship between socioeconomic status and health, the answer to this question is not known. Most prior studies that use exogenous shocks to identify the causal effects of income on health exploit natural experiments that increase income or lead to wealth accumulations; of these, only a few examine mental health outcomes. These studies show that income increases associated with lottery winnings lead to mental health improvements (e.g., Apouey

\footnotetext{
*The authors gratefully acknowledge financial support from the Russell Sage Foundation's 2011 Special Initiative on the Social and Economic Effects of the Great Recession and the National Institute on Aging (K01AG041763, Nicholas). We appreciate helpful comments on earlier drafts of this manuscript from the editor and two anonymous reviewers and from participants at the 2012 meetings of the Michigan Retirement Research Consortium, the Population Association of America, the American Society for Health Economists, the 2013 ICMPE workshop on Mental Health Policy, Economics and Health Care Reforms, and the CESIfo \& University of Munich \& MEA Conference on Empirical Health Economics, in particular, Melissa Favreault, Brooke McFall, and Nathan Tefft. Joel Segel and Elizabeth Vestal provided excellent research assistance. This study was completed while Nicholas was at the Institute for Social Research, University of Michigan.

(C) 2013 Elsevier B.V. All rights reserved.

Publisher's Disclaimer: This is a PDF file of an unedited manuscript that has been accepted for publication. As a service to our customers we are providing this early version of the manuscript. The manuscript will undergo copyediting, typesetting, and review of the resulting proof before it is published in its final citable form. Please note that during the production process errors may be discovered which could affect the content, and all legal disclaimers that apply to the journal pertain.
} 
and Clark, 2010), while receiving a bequest has no significant effect on mental health (e.g., Kim and Ruhm, 2010). However, the mental health effects of losing money have not been examined, despite the fact that a number of life events such as divorce, widowhood, and expensive medical episodes can trigger significant declines in material well-being. This may be because these events typically confound the wealth effects they engender.

Research on the consequences of wealth loss is especially important if the effect of wealth is asymmetric. Results from economics and psychology experiments provide ample evidence that individuals respond differently to losses than gains. Subjects in experiments often place a higher value on a good that they own compared to an identical good that they do not own (the endowment effect). One explanation for this effect is loss aversion, which explains that the disutility of losing a good is greater than the utility of obtaining it (e.g., Kahneman and Tversky, 1984). Further, the effects of large wealth losses may be more disruptive than generalizations of the effects of small gains or losses may suggest. It could take years of favorable stock market returns to recapture wealth losses, whereas small losses can be offset by an increase in work hours or a short-term change in consumption patterns. If the psychological or economic consequences of losses differ in these ways, then prior studies that focus on the effects of sudden gains in socioeconomic status may offer little guidance on the effects of losses on mental health.

In this study, we identify the effect of large wealth losses on mental health by focusing on the immediate and largely unexpected declines in the net worth of U.S. households brought on by the stock market crash that occurred in the fall of 2008. In the 8-day trading period that began on October 1, 2008, the closing value of the Dow Jones Industrial Average (DJIA) fell by nearly 2,400 points or roughly $22 \%$. After a small uptick, the DJIA fell throughout the month; by the end of October, the index had reached its lowest level since 2003. By December 2008, retirement accounts had lost almost one-third of their value on average, and total losses were estimated at $\$ 2.8$ trillion (Soto, 2008). Our identification strategy uses variation in the timing of interview dates for the 2008 wave of the Health and Retirement Study (HRS). Specifically, we examine respondent-specific changes in wealth and mental health between the 2006 and 2008 waves of the HRS, comparing changes for respondents whose 2008 interview took place before October of that year with the changes experienced by those interviewed after the October 2008 stock market crash. We allow the effects of the crash to vary by respondent's exposure, which we measure in pre-crash wealth in stocks and individual retirement accounts.

Respondents interviewed post-crash lost significantly more non-housing wealth between the two survey waves than respondents interviewed before the crash. Results from several falsification and placebo tests suggest that our post-crash indicator identifies the effects of the stock market crash separately from the effects of changes in the housing market or the unobservable traits of respondents interviewed later in the year.

We find mixed evidence of an effect of the crash on mental health. Subjective measures of mental health, such as "feeling depressed" and self-rated health, worsened among respondents interviewed post-crash compared to those interviewed prior to October 2008. These effects were concentrated among those respondents who lost more wealth in the crash (i.e., the wealthier half of stockholders). Although the crash had no effect on clinicallyvalidated measures of depression, respondents who lost more wealth in the crash also showed large increases in antidepressant use.

\section{Previous Literature}

A key distinction between our work and prior studies in this literature is that we examine an exogenous event that reduced wealth. ${ }^{1}$ Most prior studies identify effects of wealth or 
income through exogenous increases. These increases may result from either new public programs (Case, 2004; Frijters et al., 2005; Chung and Kim, 2011; Robert, 2011), lottery winnings (Lindahl, 2005; Gardner and Oswald, 2007; Apouey and Clark, 2010), or inheritances (Meer et al., 2003; Kim and Ruhm, 2012). Findings from these studies suggest that income from new public programs improves health status or health or life satisfaction and that winning the lottery improves mental health. In contrast, receiving a bequest appears to have no effect on various measures of health status, including ADL and IADL limitations, self-reported health, and depression (Meer et al., 2003; Kim and Ruhm, 2012), and wealth increases driven by stock market gains are not associated with improvements in physical health (Smith, 2004). ${ }^{2}$

Two prior studies examine the health effects of decreases in income. Snyder and Evans (2006) look at the effects of a legislative change affecting U.S. Social Security payments, and find that persons receiving lower incomes as a result had significantly lower mortality rates. Since reductions in Social Security, benefits may have increased employment incentives, these results may reflect the social benefits of remaining in the labor force. Sullivan and van Wachter (2009) find that job displacement led to large increases in shortterm mortality risk as well as smaller increases in long-term mortality risk. Their results imply that income losses reduce longevity since short-term earnings losses were greater than long-term earnings losses and since workers with larger earnings reductions experienced larger increases in mortality. However, neither of these studies examines mental health effects, nor can they isolate the effects of income changes versus changes in labor force attachment.

Our work differs from prior studies of income decreases in several ways. Most notably, we examine whether wealth losses have immediate effects on mental health, as opposed to longterm or even one-year effects on mortality. A focus on mental health is supported by psychology research linking wealth reductions to increased stress levels and linking increased stress with depression and other mental illnesses (see, e.g., Rabkin and Struening, 1976; Schneiderman, Ironson, and Siegel, 2005). These types 0of effects can be observed in relatively short periods of time; for example, depressive symptoms can emerge in as little as two weeks and major life events such as assault, job loss, and financial or housing problems can have mental health effects within one month (Dohrenwend, 1973; Kendler et al., 1999). ${ }^{3}$ Although other health consequences of the crash might emerge over a longer horizon, for example, by the 2010 interview, we lack the ability to identify crash effects that far out since the crash impacts every individual in the HRS by 2010 . There is also less ambiguity about the channels or mechanisms linking wealth to health compared to studies that focus on longrun risk of mortality.

A downside to our approach is the short-term relationship between wealth and health may be different from the long-term relationship. For example, looking at income increases, Evans and Moore (2011) and (2012) find that having more income causes consumption and activity levels to increase, and thereby leads to increased mortality in the short-term. Our study is unable to examine whether the effects we observe are transient or permanent, although our findings could help to elucidate some of the pathways leading to the long-term outcomes observed in other studies of income loss.

\footnotetext{
${ }^{1}$ In this section we focus on studies linking individual or household income or wealth to health status. A separate literature has examined the health consequences of macroeconomic conditions (e.g., Ruhm, 2000).

${ }^{2}$ There is some evidence that increases in income can worsen health behaviors. Kim and Ruhm (2012) report that receiving a bequest increased recreational drinking; similarly, Apouey and Clark (2010) report increased drinking and smoking by lottery winners.

${ }^{3}$ Stress may subsequently worsen physical health as elevated stress hormones take their toll on the cardiovascular and immune systems, but these effects may not be immediate (see, e.g., McEwen 1998; Schneiderman, Ironson, and Siegel, 2005).
} 
We also examine wealth fluctuations with the potential to affect a larger population of individuals compared to events like winning the lottery or receiving an inheritance. The 2008 stock market crash was unanticipated and affected asset levels for all stockholders. Because the effects of the crash were both large and sudden, our strategy differs from Smith (2004) who used stock market changes in the 1990s to identify effects on physical health. Smith found little evidence that exogenous wealth increases were timed with health improvements. As noted above, it is possible that the effects of wealth losses differ from those of wealth gains; if this is the case, our study of the events of the 2008 stock market crash may be especially informative. ${ }^{4}$

Our study also contributes to a growing literature assessing the mental health consequences of recent economic events. Currie and Tekin (2011) find that hospitalizations for psychiatric conditions increased in regions especially hard-hit by the foreclosure crisis. Other recent papers find that increases in the unemployment rate are associated with increased use of antidepressants and anti-anxiety medications (Bradford and Lastrapes, 2013) and an uptick in online, searches about depression and anxiety (Tefft, 2011). ${ }^{5}$

\section{Methodological Approach}

\subsection{Identification Strategy}

Our study employs data from several waves of the HRS, a nationally representative longitudinal survey of more than 22,000 Americans over the age of 50. Respondents are interviewed every two years and answer a wide array of questions pertaining to their household wealth, income, mental health status and behaviors, among other topics. We use HRS data from the Institute for Survey Research at the University of Michigan combined with the RAND HRS Data, version K, which include key detailed wealth measures.

We use variation in respondents' 2008 interview dates to identify the effect of the stock market crash on wealth and mental health. Figure 1 illustrates the daily closing values of the DJIA during the fielding of the 2008 wave of the HRS. While all of the HRS 2008 interviews took place during an economic recession, respondents interviewed on or after October 1 (roughly $8 \%$ of the sample in that wave) reported information about their wealth and mental health in a very different financial climate than those interviewed in the weeks and months before. Our identifying assumption is that the October 2008 stock market crash acted as an exogenous shock to the wealth of a large fraction of Americans, especially those with individual retirement accounts (IRAs) and other holdings in equity markets. Hudomiet et al. (2011) use this same strategy to study the effect of the crash on households' expectations about market returns; they also show that the 2008 interview date was not significantly associated with HRS respondents' prior stock market expectations. ${ }^{6}$

Our estimation strategy uses first-difference models of wealth and mental health to test for the effects of the crash. By examining changes between 2006 and 2008, rather than simply comparing those interviewed before and after the crash, we difference out time-invariant characteristics of respondents that might be related to both date of interview and mental health outcomes. This is a key strength of our approach, since it addresses concerns that the

\footnotetext{
${ }^{4}$ Deaton (2012) examines changes in self-reported well-being in the U.S. population from 2008 to 2011 , a period that includes the 2008 stock market crash. Using daily polling data from the Gallup Organization, he finds a sharp decline in well-being around the fall of 2008 and a close association between well-being and the S\&P 500 index between 2008 and 2010. However, the Gallup data do not include measures of wealth, so questions about the effects of the crash on wealth and how the effects on well-being vary by stock market exposure cannot be examined.

${ }^{5}$ Kuhn et al. (2009) find increased antidepressant and mental health care utilization among Austrian workers who lose jobs due to plant closure.

${ }^{6}$ Specifically, the authors show that the coefficients on 2008 interview date dummies are not statistically significant in placebo regression models of the level of and heterogeneity in respondents' stock market expectations in 2004 and 2006.
} 
respondents interviewed in the months near the end of the wave (and after the crash) are different from those interviewed earlier in some unobservable ways. In a related study, Ásgeirsdóttir et al. (2012) employ individual fixed effects models to examine the effect of Iceland's financial crisis on health behaviors; the financial crisis is measured by an indicator for 2009. Unlike their study, our identification approach employs both a treatment group (respondents interviewed post October 1, 2008) and a comparison group (those interviewed earlier) to test the effects of the crash, and we allow the treatment intensity to vary by respondent's exposure to the crash. We describe these features in more detail below. ${ }^{7}$

We first use data on respondents in both 2006 and 2008 to estimate Equation (1) below:

$$
\Delta W_{i}=\beta_{0}+\beta_{1} P O S T_{i}+\lambda \Delta X_{i}+\Delta \varepsilon_{i}, \quad(1)
$$

Here $\Delta W_{i}$ is the change in wealth between the 2006 and 2008 waves of the HRS. By including the intercept term, $\beta_{0}$, in the model, we effectively control for the common effect of being interviewed in 2008 on the wealth of all HRS, respondents in the sample. ${ }^{8}$ Thus, the key explanatory variable is POST, a dummy variable equal to 1 if the 2008 survey interview took place during or after October of that year (i.e., post-crash) and 0 otherwise. The estimated coefficient on POST represents the effect of being interviewed after the crash controlling for being interviewed in 2008. Observable differences in respondents that vary over time and may contribute to differences in wealth (such as changes in household income, employment, etc.) are represented by $X$.

We then allow the crash to have heterogeneous effects on wealth; in particular we examine whether respondents who had more "exposure" to the crash suffered greater wealth losses. We first estimate Equation (2) below:

$$
\Delta W_{i}=\alpha_{0}+\alpha_{1} \text { POST }^{*} \text { STOCK }_{i}+\alpha_{2} \text { POST }^{*} \text { NOSTOCK }_{i}+\lambda \Delta X_{i}+\Delta \varepsilon_{i}
$$

Here, STOCK equals one if the respondent held any non-zero amount of wealth in stocks or IRAs, and zero otherwise; NOSTOCK equals one if the respondent held no wealth in stocks or IRAs, and zero otherwise. These variables measure exposure to the stock market crash; we anticipate that the crash will impact respondents who own stocks and IRAs and have less of an effect on those with no stock or IRA wealth. ${ }^{9}$ We define the respondent's exposure using stock and IRA wealth in 2006 (prior to the crash); this addresses the concern that portfolio allocations in 2008 reflect assets chosen because of crash-induced mental health conditions (Bogan and Fertig, 2012). Estimates of $a_{1}$ that are negative and larger (i.e., more negative) than the estimates of $a_{2}$ would support our hypothesis.

As a second test for heterogeneous effects, we estimate Equation (3) below:

\footnotetext{
${ }^{7}$ We choose to pool all respondents interviewed before and after the October 1, 2008 cutoff instead of using a regression discontinuity approach for several reasons. First, the sample size is too small to support such an approach. Second, as we show later, not all respondents interviewed after the crash are stockholders. This would imply that a fuzzy RD approach would be more appropriate; however, the fluctuations in the DJIA shown in Figure 1 indicate that wealth loss is unlikely to be a smooth function of days from the crash. Finally, the size of the response may be proportional to the size of the loss.

${ }^{8}$ We note that in a two-period setting, the intercept in a first-differences equation captures the change from period 1 to period 2 (see $p$. 463 in Wooldridge (2006)).

${ }^{9}$ This exposure measure does not capture all of the ways a respondent's wealth could be affected by stock market events. Some respondents who have employer pensions or own mutual funds may also be exposed to the crash, and some of these respondents could have no direct holdings of stock or IRAs. However, the HRS data do not permit us to measure whether the respondent's pension or mutual fund consists of stocks or the percentage of the respondent's IRAs holdings that are held in stock, at least in our sample (Gustman et al. (2011) do so for a much smaller sample of HRS respondents). Exposure to the crash might also depend on the attributes of the respondent's pension plan, such as whether the plan is a defined contribution plan and how much of the respondent' portfolio is held in stocks.
} 
Here we allow the effects of the crash to vary across three groups of respondents: those with no wealth in stocks and IRAs (NOSTOCK), those with some wealth in stocks and IRAs (LOWSTOCK), and those with more wealth in stocks and IRAs (HISTOCK). Specifically, HISTOCK equals one if the respondent had stock and IRA wealth levels at or above the median wealth of stockholders (in terms of wealth in stocks and IRAs, not their overall wealth), and zero otherwise; LOWSTOCK equals one if the respondent had stock and IRA wealth levels that placed them in the less wealthy half of stockholders (again, in terms of the amount of wealth in stocks and IRAs), and zero otherwise. ${ }^{10}$ Again we expect that exposure increases with the amount of wealth held in stocks/IRA; this specification allows the effects of increased exposure to be non-linear. As in equation (2), respondent exposure is based on 2006 wealth holdings. In this case, support for our hypothesis would come from negative estimates of $\delta 1$ that are larger (i.e., more negative) than estimates of $\delta_{2}$ and $\delta_{3}$. We estimate Equations (1) through (3) for both absolute changes in wealth and proportional changes in wealth (i.e., changes in the natural $\log$ of wealth). Proportional changes may be more salient to respondents given the way stock market performance is reported and in light of diminishing marginal utility in wealth. ${ }^{11}$

To examine the effect of crash-induced wealth losses on health, we estimate Equation (4) below:

$$
\Delta H_{i}=\delta_{0}+\delta_{1} \text { POST }^{*} H I S T O C K_{i}+\delta_{2} \text { POST }^{*} L O W S T O C K_{i}+\delta_{3} \text { POST NOSTOCK }_{i}+\lambda \Delta X_{i}+\Delta \varepsilon_{i}
$$

where $H$ represents one of several clinical and subjective measures of mental health described below. This reduced form specification also allows the effects of the crash to vary by the respondent's exposure to the crash.

\subsection{Data}

We estimate our regression models using two samples of HRS respondents constructed as follows. Of the combined respondents to the 2006 and 2008 waves (35,686 respondents), we include respondents with non-proxy interviews in both waves $(n=30,508)$, designated as the financial respondent in the household in both waves $(n=20,708),{ }^{12}$ and born no later than $1953(n=20,040) .{ }^{13}$ The resulting sample includes 10,020 unique financial respondents. We also define a second estimation sample that excludes respondents in the top $1 \%$ and the bottom $1 \%$ of 2006 non-housing wealth, leaving us with 19,642 respondents in both years, or 9,821 unique respondents.

Table 1 reports descriptive statistics for the first estimation sample by year of interview and for respondents interviewed after the 2008 crash. Our main measure of wealth is real non-

\footnotetext{
${ }^{10}$ In results described below, we also tested an alternative definition of exposure to the crash. In these alternative specifications, we estimate equation (3) but instead define LOWSTOCK and HISTOCK based on the percentage of the respondent's portfolio that is held in stock/IRA assets.

${ }^{11}$ While a large literature also explores the health effects of relative income (income compared to one's peers, for example), we do not pursue that approach because of the challenge of identifying the appropriate reference groups in the HRS.

${ }^{12}$ There is one financial respondent for almost every household interviewed in the HRS. In one-respondent households, the sole respondent is the financial respondent; in two-respondent households, the financial respondent answered household-level financial questions on behalf of the entire household. This respondent was determined based on the answer to the question: "Which member of your immediate family is most knowledgeable about your family's assets, debts and retirement planning?"

${ }^{13}$ We exclude persons born after 1953 because the HRS was designed to be representative of individuals aged 51-61 and the youngest cohort added to the 2008 HRS core sample of respondents was born no later than 1954. This exclusion leads us to drop spouses of age-eligible persons who, while interviewed, were not the focus of the sample design.
} 
housing wealth, reported in 2008 dollars. This is defined in the RAND HRS data as the total of non-housing assets less debt, where non-housing assets are the amounts of wealth held in checking and savings accounts, CDs, savings bonds and Treasury bills, bonds, total IRA accounts, stocks, mutual funds, real estate other than housing, vehicles, businesses, plus other savings and assets. On average, real non-housing wealth declined from $\$ 344,491$ in 2006 to $\$ 292,861$ in 2008 . As expected, the size of this decline was more severe among the respondents whose 2008 interview took place on or after October 1 of that year. For that group of 815 respondents, non-housing wealth fell by an average of $46 \%$, from $\$ 506,150$ in 2006 to $\$ 271,484$ in $2008 .{ }^{14}$ Mean changes in non-housing wealth are large in magnitude because losses are concentrated among households with sufficient wealth to have stock market exposure. The mean household experienced losses of \$51,630 from 2006 to 2008, while the median household reported losses of only $\$ 5,889$.

Non-housing wealth is our preferred wealth measure because it includes IRA accounts which are likely to be impacted by the crash. As a robustness check we also examine financial wealth, defined in the RAND HRS data as total financial assets less debt, including checking and savings accounts, CDs, savings bonds and Treasury bills, bonds, stocks, mutual funds, plus other savings and assets, but excluding IRA accounts. However, this exclusion makes financial wealth less suitable for our study because IRA account owners face considerable exposure to the market. Gustman et al. (2011) report that, among the early boomer HRS cohort, $73 \%$ of IRA assets were held in stocks (see Table 1 of their study).

We use six measures of HRS respondents' mental health. The first two are clinicallyvalidated measures of depressive symptoms or depression based on the Center for Epidemiologic Studies Depression or CES-D scale, which was designed to measure depressive symptoms in the general population (Radloff, 1977). The HRS version of the CES-D includes eight of the 20 items in the standard index; the items ask respondents to report whether or not in the past week they felt depressed, happy, lonely, sad, etc. ${ }^{15} \mathrm{We}$ create a CES-D index by summing the number of negative symptoms and reverse coding the positive symptoms (Steffick, 2000), so that higher values of the index indicate more depressive symptoms. We also employ a binary indicator equal to 1 if the respondent reports three or more depressive symptoms from the CES-D scale and 0 otherwise. As Shane et al. (2008) report, a score of three or more on the eight-item CES-D corresponds with a score of 16 or more on the 20 -item CES-D, which indicates clinical depression. This measure has been used as an indicator of major depression in the HRS following validation by Turvey et al. (1999). We also use a binary indicator equal to one if the respondent reported regularly taking prescription medications to help relieve anxiety or depression and 0 otherwise.

We then examine several subjective measures of mental health; these outcomes help to capture feelings of depression that may occur absent a diagnosis of clinical depression. We examine a binary indicator equal to one if the respondent reported "feeling depressed" in the past week, and zero otherwise. We also examine two measures of self-reported health; one is a scale measure ranging from 1 (poor) to 5 (excellent); the other is a binary indicator for excellent/very good health. Schnittker (2005) shows that self-reported health status is closely associated with mental health among older adults.

\footnotetext{
${ }^{14}$ Note that this is the combined decline in wealth from losses and sales. Respondents who sold stock after their 2006 interview can be identified in the 2008 wave, but the specific dates of stock sales are not identified; therefore we are unable to examine the link between decisions to sell stock and the stock market crash.

${ }^{15}$ Four other items in the 8-item CES-D scale ask whether "everything is an effort", whether "sleep is restless", and whether the respondent "enjoys life" and "cannot get going." The HRS also contains a short form of the Composite International Diagnostic Interview (CIDI-SF) but because these interview questions pertain to symptoms within the last 12 months and because we are interested in symptoms experienced at the interview date, we do not use it in our analysis.
} 
As seen in Table 1, there was a slight decline among all respondents in both the CES-D index and the indicator for having three or more depressive symptoms from 2006 to 2008. Among respondents interviewed post-crash, mean CES-D and the proportion of respondents with three or more depressive symptoms decreased over time to a lesser extent than in the full sample. A similar pattern is observed for subjective feelings of depression: the share of all financial respondents who reported feeling depressed fell from $16.8 \%$ to $13.4 \%$ between 2006 and 2008, but among those whose 2008 interview took place post-crash, there was a smaller decline from $18.2 \%$ to $16.6 \%$. The proportion of all financial respondents taking antidepressants was relatively stable between 2006 and 2008, but it rose by nearly one percentage point among those interviewed post-crash.

Table 1 also compares post-crash respondents to the full sample in terms of their demographic, economic, and other traits. Respondents interviewed later in the year in 2008 are younger, have higher household incomes, and are more likely to work and less likely to be retired. This pattern is consistent with reports that respondents interviewed later in the wave are those who are hardest to schedule. ${ }^{16}$ Post-crash respondents are similar to the larger sample in terms of sex, race, education, marital status, and cognitive function. We looked for evidence of hard-to-observe differences in current health status by comparing the percentage of 2008 financial respondents who died by 2010 by broadly-defined interview dates. Mortality rates were fairly similar; $7.8 \%$ of respondents interviewed in the first six months of the 2008 wave (February-June 2008) had died by 2010, compared to $7.6 \%$ of respondents interviewed in the last six months of the 2008 wave (September 2008-February 2009). Nonetheless, to address concerns about differences in the post-crash group that might be correlated with wealth and/or mental health, our regression models include a number of controls for time-varying individual or household traits. The full set of explanatory variables includes measures of cross-wave transitions in marital status, employment status, and retirement status, ${ }^{17}$ changes in household income and its square, changes in household size and cognitive function, controls for the onset of various physical health conditions across waves, ${ }^{18}$ the time between waves (measured in months and months squared), and two indicator variables to control for changes in the season in which the interview takes place. ${ }^{19}$ As noted above, the first-difference specification controls for time-invariant traits that may be correlated with the post-crash indicator and our outcomes of interest, whether these traits are observed (such as race, sex, education) or unobserved (such as risk preference). ${ }^{20}$

\footnotetext{
${ }^{16}$ See Hudomiet et al. (2011), who also state that respondents interviewed later may be harder to locate and more reluctant to be interviewed (p. 402).

${ }^{17}$ Controls for both retirement and employment status are included because some respondents are employed during retirement. Cognitive impairment is associated with depression and may also be associated with changes in spending for nursing home care and thus wealth.

${ }^{18}$ The physical health conditions are cancer, diabetes, heart disease, lung disease, stroke, arthritis, and hypertension. We include separate indicators for each condition. To preserve sample sizes we also include a set of controls for whether the respondent is missing data on a given indicator, and then recode the indicator to zero.

${ }^{19}$ The designation known as SAD, or seasonal affective disorder, links the onset of depressive symptoms to decreases in daylight timed with fall and winter months. For example, Tefft (2012) shows that more hours of darkness are associated with adverse mental health and employment outcomes. These controls help to account for the possibility that respondents in our sample were interviewed at different times of the year in the 2006 and 2008 waves and that the onset of seasonal depression might be correlated with being interviewed post-crash in 2008. We include a dummy equal to one if the respondent's interview changed from a fall/winter month to a spring/summer month between 2006 and 2008 (and zero otherwise), and a second dummy equal to one if the respondent's interview changed from a spring/summer month to a fall/winter month across the two waves (and zero otherwise). Certain HRS design features (namely an oversample of both Floridians and Hispanics) also help to mitigate concerns of SAD for respondents who live in regions with perpetually summery weather. We obtained similar results when we used a set of month of interview dummy variables in place of the seasonal change in indicators.

${ }^{20}$ It is possible that some of the control variables are themselves affected by the crash (e.g., income). As a robustness check, we examine the sensitivity of our results to the exclusion of household income and other controls. These results are described below.
} 


\section{Empirical Results}

\subsection{Effects of the Stock Market Crash on Wealth}

Table 2 presents estimates of the effects of the crash on absolute changes in respondent wealth, where wealth is measured as total non-housing wealth. Columns (1) and (2) report the estimated post-crash coefficient from Equation (1) using the sample of all financial respondents and then excluding the top and bottom $1 \%$ of the wealth distribution. In the full sample, the crash had a statistically significant effect on non-housing wealth, reducing it by more than $\$ 238,000$. In the trimmed sample, the crash reduced wealth by almost $\$ 44,000$, but the effect is not statistically significant. The sizes of these effects are consistent with the asset declines reported by Bricker et al. (2012).

The remaining columns of Table 2 illustrate the importance of allowing for heterogeneous effects. We first allow the effect of the crash to vary between those with any stock/IRA wealth in 2006 (who comprise $47.2 \%$ of respondents) and those with no stock/IRA wealth (the remaining 52.8\%), as in Equation (2). In columns (3) and (4) we report the post-crash coefficients from this equation for both the full and the trimmed samples. In both samples, the post-crash coefficient defined for stockholders $\left(P O S T^{*} S T O C K\right)$ is negative and significant, and much larger in absolute value than the post-crash coefficient defined for nonstockholders. The estimated post-crash coefficient for non-stockholders is also statistically insignificant. The results from the trimmed sample, for example, suggest that the crash caused wealth declines of more than $\$ 81,000$ among respondents with any stock/IRA wealth, but led to no significant changes in wealth for respondents without stocks or IRAs.

We then allow the effects of the crash to vary across respondents in the top half of the stock/ IRA wealth distribution in 2006 ( $23.6 \%$ of respondents), those in the bottom half of the stock/IRA wealth distribution (another 23.6\%), and those with no stock/IRA wealth (the remaining 52.8\%). As seen in columns (5) and (6) the crash effect varies by exposure in both the full and trimmed samples. Effects are largest for those in the top half of the stock/ IRA wealth distribution (e.g., in the trimmed sample, the crash caused wealth losses of $\$ 223,581$ ), and statistically insignificant for the other types of respondents. Results from $\chi^{2}$ tests in both samples allow us to reject the null hypothesis that the post-crash coefficients are equal among the top half of stockholders and the non-stockholders $(p<0.001){ }^{21}$

Table 3 presents regression results from models of proportional changes in respondent wealth. The sample sizes are about $20 \%$ smaller because several hundred respondents in each year report zero or negative values of total non-housing wealth. Although the average post-crash effect is not statistically significant (in columns 1 and 2), there are significant heterogeneous effects that vary by the respondent's exposure to the crash. Respondents who had some stock or IRA wealth in 2006 lost about $27-30 \%$ of their total non-housing wealth as a result of the crash, and respondents in the top-half of the stock/IRA wealth distribution in 2006 lost about half of their wealth as a result of the crash. As a robustness check, we estimate models from Tables 2 and 3 using financial wealth as a dependent variable; recall that this more narrowly-focused measure includes stocks and mutual funds but excludes IRA accounts. As expected the coefficients of the post-crash indicator variable and interaction

\footnotetext{
${ }^{21}$ We also estimated models of non-housing wealth where we allowed the effect of the crash to varyacross respondents with no stock/ IRA wealth, those with low stock/IRA wealth, and those with high stock/IRA wealth (as in Table 2, columns 5 and 6), but in which we defined "high" and "low" stock/IRA respondents based on the share of the respondent's wealth held in stocks/IRAs (instead of the level). That is, high stock respondents were those whose share of wealth in stocks/IRAs was above the median share among stock/IRA owners, and low stock respondents are those whose share of wealth was below the median. The share is defined as the amount of wealth in stocks and IRA divided by the total value of wealth including the value of a second home. Because this approach uses two wealth measures, it introduces some measurement error in the post interaction terms and yields a slightly smaller sample because of missing values in total wealth. Results are available upon request.
} 
terms are smaller, but the pattern is the same as that seen for non-housing wealth (see Appendix Tables A1 and A2). Clearly, the events on Wall Street had very different effects on wealth depending on a given respondent's exposure to the stock market.

\subsection{Falsification and Placebo Tests}

While the stock market crash was closely timed with the start of October 2008 (see Figure 1), the post-crash coefficients could be picking up effects of other coincident events or correlated factors, and not the effect of the crash per se. For example, the downturn in the housing market is particularly important to consider since the housing crisis itself may have led to worsening mental health. ${ }^{22}$ Another possibility is that there is something unobservable about the respondents interviewed late in the 2008 wave of the HRS that makes them more prone to wealth losses than the other respondents, regardless of what is happening on Wall Street. For example, these respondents may have preferences for more aggressive portfolio allocations and experience greater wealth volatility. Even though we estimate first-difference models, we examine both of these possibilities.

First, we consider whether the post-crash indicators could be picking up declines in housing wealth. This is possible since our broadly-defined measure of non-housing wealth includes real estate other than housing. We examine the timing of the housing crisis relative to October 2008 using data from the Federal Housing Finance Authority's House Price Index. ${ }^{23}$ Figure $2 \mathrm{~A}$ plots the index, based on all transactions, which includes new home purchases and refinancing appraisals for existing homeowners; these data represent the most comprehensive information respondents might have about the value of their home. Figure 2B plots seasonally-adjusted data based on home sales only. In each graph, we show national trends (solid line) and the trend at the time of HRS interview (dashed line). The HRS trends are constructed by matching HRS respondents to housing information for their state of residence during the quarter of their interview. Both figures show that the HRS sample is representative of national trends, and moreover, that the housing crisis began much earlier than the October 2008 crash. Figure 2A suggests that, if anything, national housing prices were starting to recover in the post-crash period relative to the pre-crash period. As a result, respondents interviewed after the crash may report smaller changes in real estate values than pre-crash respondents. Thus, any confounding of our estimates from the foreclosure crisis and decline in housing wealth should bias us towards finding no effect of the crash.

We next conduct a falsification test using housing wealth as defined by HRS respondents. For this exercise, we estimate the same series of models shown in Equations (1) through (3) and where the dependent variable is housing wealth. Table 4 reports results from models of the net value of the primary residence. We see no evidence that respondents interviewed after October 2008 saw declines in housing wealth. In all but one case, the coefficients of the post-crash indicator or the post-crash interaction terms are positive. We get similar results when we use a, dependent variable defined as the gross value of the primary residence (results are available upon request). ${ }^{24}$

\footnotetext{
${ }^{22}$ For example, Currie and Tekin (2011) find that the foreclosure crisis was associated with an increase in medical visits for anxiety, suicide attempts, and stress-related physical complaints.

${ }^{23}$ Figures 2A and 2B report the Purchase Only Index and All Transactions Index, US Summary and Census Divisions through 2012Q1 and States through 2012Q1, obtained from the Federal, Housing Authority and available at http://www.fhfa.gov/ Default.aspx?Page $=87$ (accessed 6 August 2012). The All Transactions Index includes data on refinancing and home purchases, while the Purchase Only Index includes only home purchases. National data are reported monthly, and state-level totals are available quarterly.

${ }^{24}$ These results might also be evidence that respondents' assessments of the value of their homes are very imprecise.
} 
Next, we consider the possibility that respondents interviewed late in 2008 differ in some unobservable way that makes them more prone to wealth losses across waves, regardless of events in the stock market. We estimate a series of placebo regressions similar to the specifications shown by Equations (1) through (3), but in which the dependent variable is the change in wealth between 2004 and 2006 and the POST indicator is, as before, defined from the date of interview in 2008. Evidence that a post-crash interview date in 2008 is not associated with changes in wealth, relative to the comparison group, would provide the strongest support for our identification strategy. ${ }^{25}$ This test serves as an effective placebo test regarding wealth changes in 2008 if there were no sizable changes in stock market returns between 2004 and 2006 and if the treatment group (i.e., those interviewed at the end of the 2008 survey) were evenly distributed across the 2006 survey dates. However, the DJIA closing values did not remain flat through the 2006 wave, and instead were generally increasing over the months that the 2006 survey (wave 8 ) was fielded. ${ }^{26}$ In addition, those interviewed post-crash in 2008 (at the end of the 2008 survey period) were more than twice as likely to have been interviewed at the end of the 2006 survey period. For these reasons, we might expect the treatment group to experience an increase in wealth between 2004 and 2006 relative to the comparison group. That is, since our treatment group was also more likely to be interviewed late in the fielding of the 2006 HRS, the higher stock returns at the end of this survey period are expected to result in, larger gains for the treatment group between 2004 and 2006. Although this means that these placebo regressions might also be picking up changes in wealth that are a result of changes in the stock market, it does allow us to test whether the treatment group is more prone to wealth losses than the comparison group.

Results from this exercise are reported in Table 5. There is no evidence that respondents with a post-crash interview in 2008 were more likely to experience wealth losses between the 2004 and 2006 waves. As expected, there is some evidence that respondents interviewed in October 2008 or later had larger wealth increases. We conduct a similar series of placebo tests in which the dependent variable is the change in financial wealth across the 2004 and 2006 waves. The results, reported in Appendix Table A3, are similar. In no case is having a post-crash interview date in 2008 associated with significant declines in wealth across the earlier waves. Even though there may be some differences between respondents interviewed in October 2008 or later and those interviewed earlier in the year, we find no evidence that the treatment group is more prone to sizable reductions in wealth.

\subsection{Effects of the Stock Market Crash on Mental Health}

Table 6 reports the reduced form estimates of the effects from the stock market crash on six different measures of mental health. The top panel reports results from models of clinicallyvalidated depression measures based on the CES-D index and from a model of antidepressant use. The bottom panel reports results using subjective measures of mental health.

Columns 1 and 2 report the estimated effects of the crash on the number of depressivesymptoms. Respondents who owned no stock/IRA accounts were not affected by the crash, while thewealthier half of stockholders reported more depressive symptoms after the crash. However, thelatter effect is not statistically significant, and the less wealthy half of stockholders reported significantly fewer depressive symptoms after the crash than the other groups. Columns 3 and 4, report results from models of having three or more symptoms from the CES-D scale; these provide little evidence that the crash led to clinically

\footnotetext{
${ }^{25}$ This placebo test is similar to the one reported in Hudomiet et al. (2011).

${ }^{26}$ Between March and September 2006, the closing value of the DJIA ranged from 10,667 to 11,718. The closing value was higher in the latter half of the survey period, ranging from 11,670 to 12,786 between October 2006 and February 2007.
} 
significant increases in depressive symptoms. None of the post-crash interactions is statistically significant, and the crash effect is relatively large and negative among respondents who hold less than the median value of stock wealth. ${ }^{27}, 28$

Despite the absence of effects on clinically-validated measures of depression, the results in columns 5 and 6 suggest that antidepressant use increased following the stock market crash among those with large stock holdings. Antidepressant use rose among the wealthier half of stockholding respondents by 6.2 percentage points, or nearly $35 \%$ from a base of 17.6 percent. We tested whether this medication use masked an increase in major depression by reclassifying respondents reporting anti-depressant use as having 3 or more symptoms; again we fail to find significant changes in clinical depression among those affected by the crash.

An interesting question is whether increased antidepressant use that occurs without a corresponding uptick in clinical depression represents "inappropriate" medication use, although the HRS limits our ability to differentiate between inappropriate use and successful treatment of depressive episodes that emerge between HRS waves. Nonetheless, our antidepressant result is robust to specifications excluding all respondents who did not meet the clinical depression threshold in either 2006 or 2008 but began taking antidepressants between their 2006 and 2008 interviews. The POST x HIGH STOCK interaction term remains positive and statistically significant, although the coefficient is smaller (at 0.049 , compared to 0.062 in the main estimation sample). Bradford and Lastrapes (2013) find an increase in the use of antidepressants without an increase in mental health office visits during times of rising unemployment; they note that this might represent the use of prescription drugs to substitute for potentially more costly (in terms of co-payments, patient time, or both) office-based treatments by mental health professionals.

Although the crash had no effect on indicators of clinical depression, the results inthe bottom panel of Table 6 show that it increased the likelihood of feeling depressed among the wealthier half of stockholding respondents. For that group, the stock market crash increased the probability of feeling depressed by 8.2 percentage points, or nearly $50 \%$ from a base of 16.6 percent. $^{29}$ The remaining columns of Table 6 also provide evidence that the crash worsened subjective measures of health among respondents with relatively large holdings in stock. Specifically, both groups of stockholders reported significantly worse self-rated health post-crash, and the post-crash coefficient is larger for the wealthier half of stockholders than it is for the less wealthy half. Interestingly, the crash-induced reductions in self-reported health are driven by a decline in respondent reports of very good or excellent health, and not from an increase in fair or poor health (results from models of fair/poor health are available upon request). This may be explained by the fact that respondents with more wealth (and more stock market exposure) are, overall, more likely to report excellent or very good health and less likely to report fair or poor health.

We tested the robustness of the health findings to various specification changes. First, we examined how sensitive our results were to alternate definitions, of the treatment and control groups, since Figure 1 suggests that the DJIA began to experience some declines in June (although these declines were much smaller than those experienced in the fall 2008), and in

\footnotetext{
${ }^{27}$ Results were very similar when the dependent variable was defined as 1 if the respondent had four or more depressive symptoms (and 0 otherwise).

${ }^{28}$ Since antidepressants may mask depressive symptoms, we tested whether there was an impact of large wealth losses on this clinically-validated measure of depression when we exclude individuals who report taking antidepressants in either 2006 or 2008 from the estimation sample. We still find no effect.

${ }^{29}$ Additional analysis also shows a longer lag in antidepressant use than in feelings of depression following the crash. In results available upon request, we find a large increase in the likelihood of feeling depressed in the month of and the month following the crash; in contrast, increases in the likelihood of taking antidepressants are larger at two to three months post-crash than in the month of and the month after the crash.
} 
light of the various events taking place in the summer and early fall of 2008, such as the declining value of Fannie Mae and Freddie Mac stocks and the bankruptcy filing by Lehman Brothers Holdings, Inc. In one specification we used all respondents and defined the treatment group as those interviewed from June 2008 on; we obtained similar results but the size of the crash effects on wealth, feelings of depression and self-rated health were smaller, as would be expected. In another specification we excluded respondents interviewed between June and September and defined the treatment group as those interviewed from October 2008 on; we obtained larger point estimates for the effects of the crash on feelings of depression and excellent/very good self-reported health, but in the latter case, the standard errors increased (perhaps not surprising since the sample size fell by 37\%). In one set of models, we dropped controls for the household income and physical health conditions, given the possible endogeneity of the variables. In another set of models, we dropped all controls including those for changes in cognitive impairment and transitions in marital status, work and retirement. We added a control of the onset of mental health chronic conditions, which we originally excluded out of concerns about endogeneity. In almost all cases, the results are substantively the same as those reported in Table 6.

We estimated a set of placebo regressions similar to those shown for wealth; these use the changes in mental health measures between 2004 and 2006 as the dependent variables, and a set of "fake" post-crash variables as the key explanatory variables. Table 7 shows the results; since the 2004 wave of the HRS does not contain the question on antidepressant use we are unable to conduct a placebo test with this measure. Evidence that the fake post-crash variables worsened mental health among respondents with stock and IRA holdings would, call our identification strategy into question. In contrast, Table 7 shows that respondents interviewed later in 2008 did not experience worsening mental health between the 2004 and 2006 waves. That said, we do not see improvements in subjective mental health for the wealthier half of stockholders despite the fact that we see positive impacts on wealth for this group (in Table 5). This may be explained by asymmetric effects of wealth on mental health, which may also help to reconcile our results with those from Smith (2004), who reported that the gradual stock market wealth accumulations in the 1990s were not associated with improvements in physical health.

Finally, we explored the possibility of using the post-crash indicators to instrument for changes in wealth. For this to be a valid identification strategy, the crash of 2008 must affect respondents' mental health only through its effect on wealth. Both theoretical arguments and first-stage diagnostic testing raised concerns about the validity of this approach. For example, the crash could impact other types of wealth that we are not able to measure (e.g., pension plan accumulations) or the crash could impact mental health by raising anxieties about children's financial or employment prospects in addition to own wealth losses. For this reason, the exclusion restriction would not be satisfied.

\section{Summary and Discussion}

In this study we exploit the exogenous variation in wealth created by the crash to address a question of long-standing interest in the health economic and social epidemiology literatures: what is the causal effect of wealth on different dimensions of health? Our study adds to a number of careful studies in the area but is unique in that we examine the immediate effects of sudden wealth losses on mental health. In comparison, the prior studies on the effects of income losses focus on mortality, and the prior studies on mental health effects examine increases in income.

We find new evidence that the stock market crash of 2008 altered subjective measures of mental health for respondents with large holdings of stock. In reduced form specifications, 
we estimate that respondents whose wealth was most affected by the crash (and who lost nearly $\$ 250,000$ as a result), had a nearly $50 \%$ increase in the likelihood of feeling depressed and a nearly $20 \%$ reduction in the likelihood of reporting excellent or very good health. However, we find no evidence that the wealth losses associated with the crash affected clinically-validated measures of depressive symptoms and indicators of depression. Respondents whose wealth was most affected by the crash experienced no significant changes in a summary score from the CES-D scale for depression or in a binary indicator of depression based on having three or more symptoms. Despite there being no change in signs of clinical depression, respondents who experienced large wealth losses and reductions in subjective health also exhibited a sizeable $35 \%$ increase in the likelihood of taking antidepressants. One explanation for this pattern of findings is that respondents who experience wealth losses deal with the resulting bad feelings by using antidepressant drugs inappropriately, i.e., when clinical symptoms of depression are not present. If so, this suggests a need for additional studies to support clearer guidelines for antidepressant use and prescribing practices, particularly pharmacological treatments for patients who have experienced shocks such as job loss or death of a loved one, a controversial clinical area (e.g., Mazure et al., 2000; Simon, 2013). Alternatively, the increased medication use may reflect prophylactic prescription use that staved off major depressive episodes; a growing literature suggests that use of mental health treatments increases among groups exposed to adverse macroeconomic conditions.

A limitation of our study is that we use an identification strategy that permits us to examine only the short-term mental health effects of the crash. Prior studies have found that subjects interviewed nearly two years after devastating events that result in large financial losses (e.g., involuntary job loss and bank fraud) showed increased rates of clinical depression (Gallo et al., 2000; Ganzini et al., 1990). Even though we do not observe immediate increases in clinically-validated measures of depression following large wealth losses, there may be more severe long-term consequences that we are unable to quantify.

Finally, this study contributes to the literature on the health consequences of adverse economic shocks, which includes studies of the recent U.S. foreclosure and economic crises by Currie and Tekin (2011), Deaton (2012) and Burgard et al. (2012) and research on Iceland's financial crisis by Ásgeirsdóttir et al. (2012). Like these other works, our study finds that severe macroeconomic events have important consequences for health, in addition to their effects on retirement plans and expectations (Coile and Levine, 2009; McFall, 2011).

\section{Appendix Table A1: Absolute Changes in Financial Wealth, 2006 to 2008}




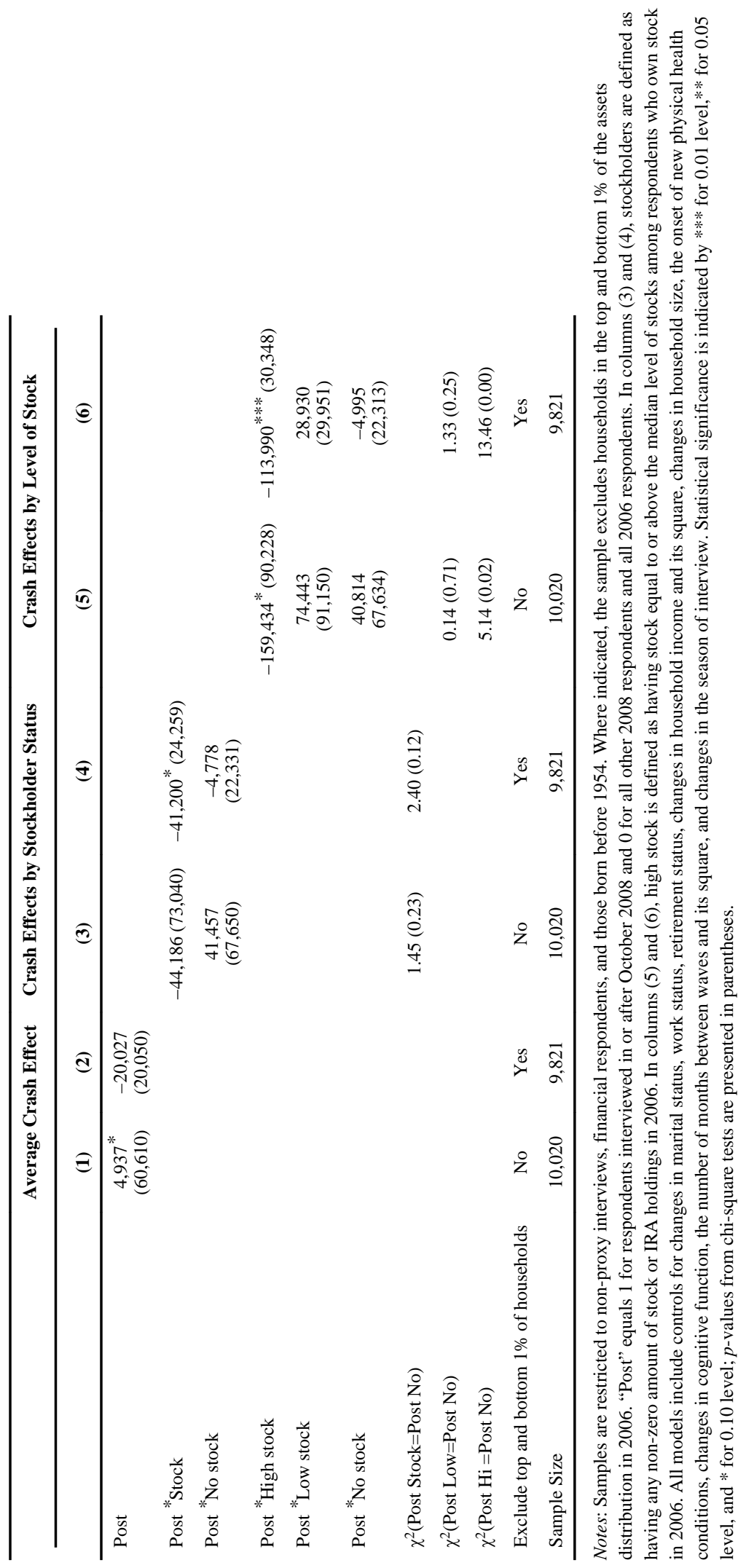


Appendix Table A2: Proportional Changes in Financial Wealth, 2006 to 2008 


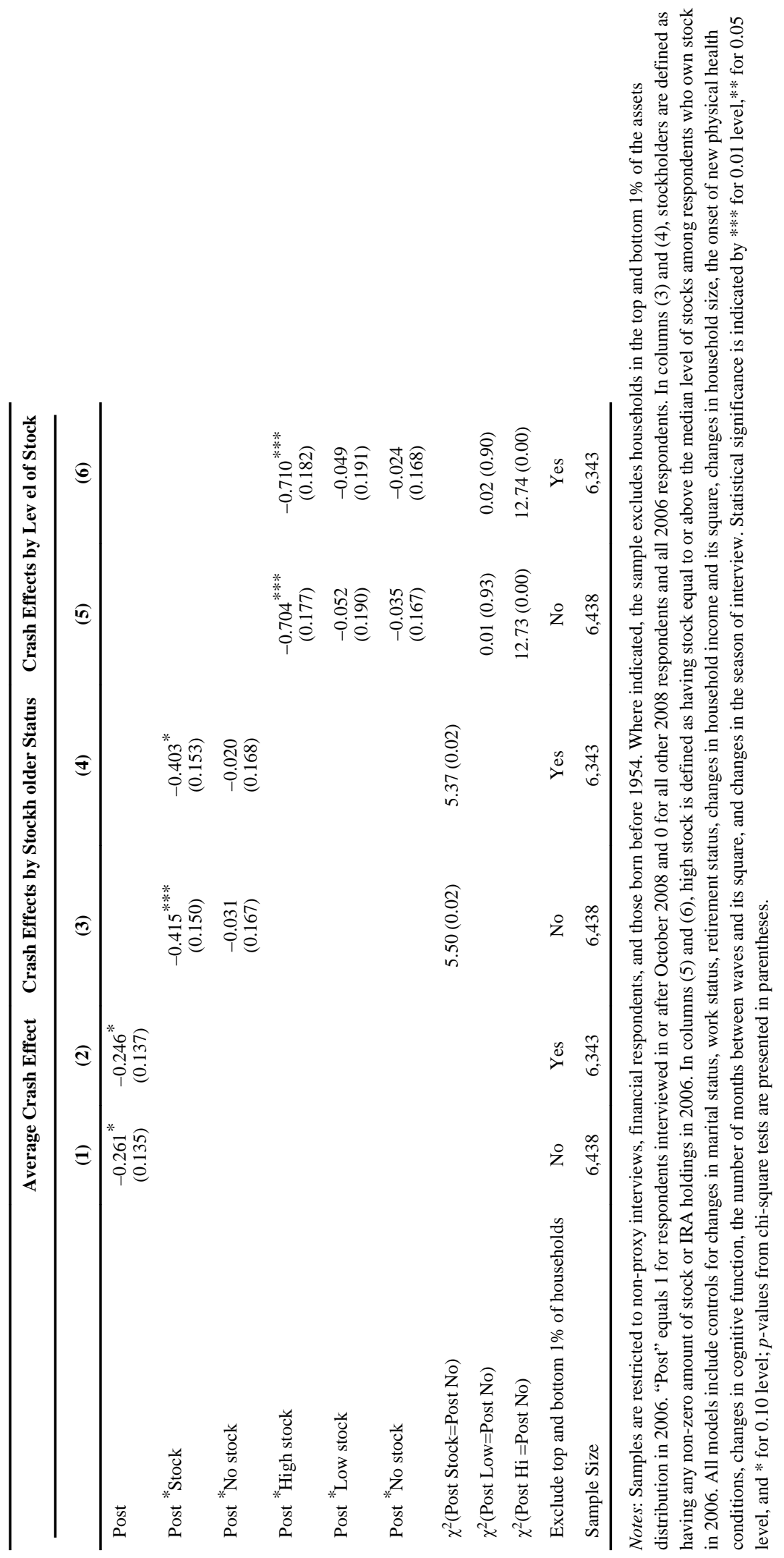


Appendix Table A3: Placebo Effects on Changes in Financial Wealth, 2004 to 2006 


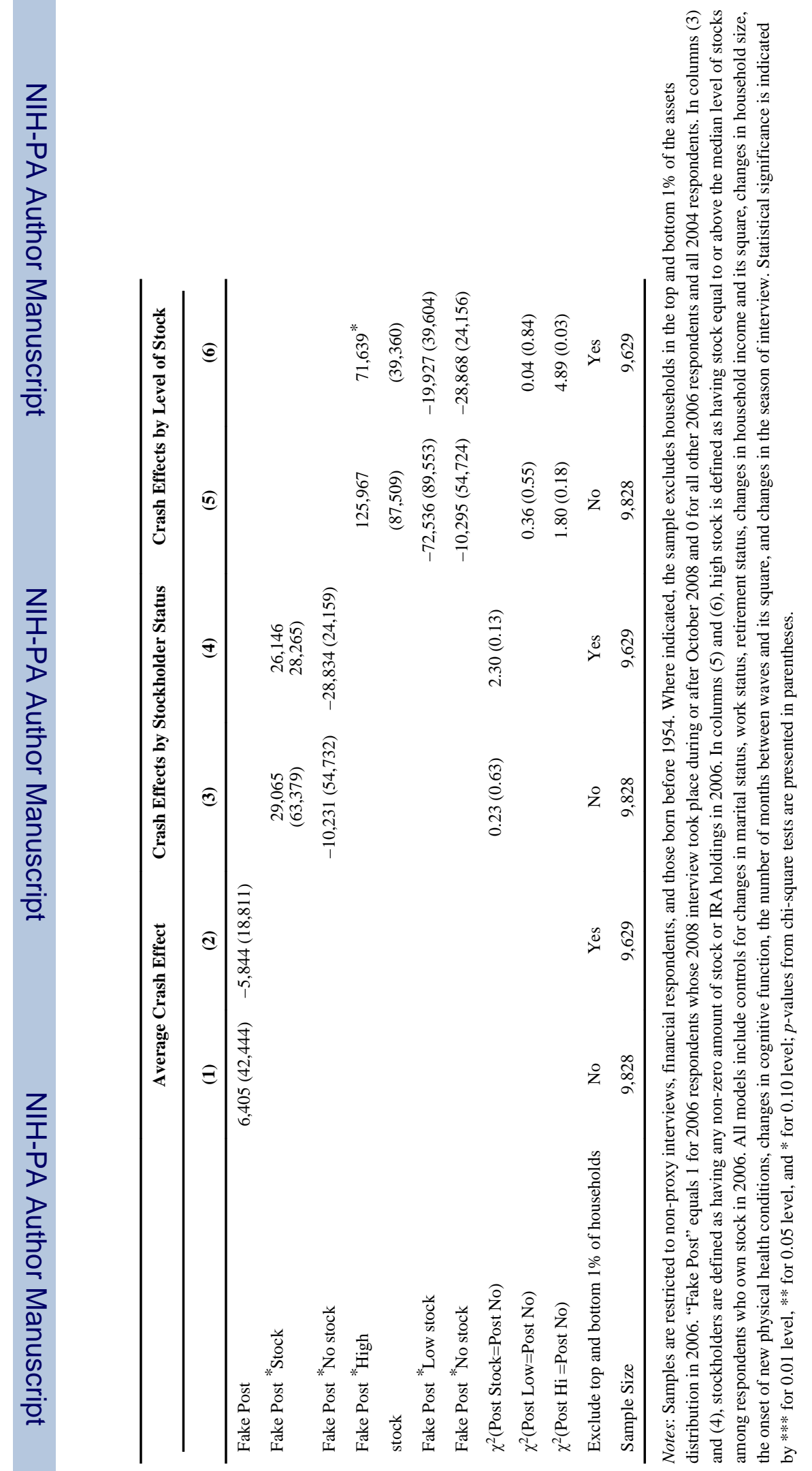

$J$ Health Econ. Author manuscript; available in PMC 2014 December 01. 


\section{References}

Apouey B, Clark AE. Winning Big But Feeling No Better? The Effect of Lottery Prizes on Physical and Mental Health. 2010 Jan. IZA Discussion Paper No. 4730.

Ásgeirsdóttir TL, Corman H, Noonan K, Ólafsdóttir Pórhildur, Reichman NE. Are Recessions Good for Your Health Behaviors? Impacts of the Economic Crisis in Iceland. 2012 Jul. NBER Working Paper No. 18233.

Bogan VL, Fertig AR. Portfolio Choice and Mental Health. Review of Finance. 2012 forthcoming.

Bradford WD, Lastrapes WD. A Prescription for Unemployment? Recessions and the Demand for Mental Health Drugs. Health Economics. 2013 forthcoming.

Bricker J, Kennickell AB, Moore KB, Sabelhaus J. Changes in U.S. Family Finances from 2007 to 2010: Evidence from the Survey of Consumer Finances. The Federal Reserve Bulletin. 2012; 98(2)

Burgard S, Seefeldt K, Zelner SW. Housing Instability and Health: Findings from the Michigan Recession and Recovery Study. 2012 Jan. PSC Research Report No. 12-749.

Case, A. Does Money Protect Health Status? Evidence from South African Pensions. In: Wise, DA., editor. Perspectives on the Economics of Aging. Chicago: University of Chicago Press; 2004.

Chung W, Kim B. Money Transfer and Birth Weight: Evidence from Alaska. 2011 Working paper.

Coile C, Levine PB. The Market Crash and Mass Layoffs: How the Current Economic Crisis May Affect Retirement. 2009 Oct. NBER Working Paper No.15395.

Currie J, Tekin E. Is there a Link Between Foreclosure and Health? 2011 Aug. NBER Working Paper No. 17310.

Deaton A. The Financial Crisis and the Well-Being of Americans. Oxford Economic Papers. 2012; 64:1-26. [PubMed: 22389532]

Dohrenwend BS. Life Events as Stressors: A Methodological Inquiry. Journal of Health and Social Behavior. 1973; 14(2):167-175. [PubMed: 4717129]

Evans WN, Moore TJ. The Short-Term Mortality Consequences of Income Receipt. Journal of Public Economics. 2011; 95(11):1410-1424.

Evans WN, Moore TJ. Liquidity, Economic Activity, and Mortality. Review of Economics and Statistics. 2012; 94(2):400-418.

Frijters P, Haisken-DeNew JP, Shields MA. The Causal Effect of Income on Health: Evidence from German Reunification. Journal of Health Economics. 2005; 24:997-1017. [PubMed: 16129130]

Gallo WT, Bradley EH, Siegal M, Kasl SV. Health Effects of Involuntary Job Loss Among Older Workers: Findings from the Health and Retirement Study. Journal of Gerontology: Social Sciences. 55B(3):S131-S140.

Ganzini L, McFarland BH, Cutler D. Prevalence of Mental Disorders after Catastrophic Financial Loss. Journal of Nervous and Mental Disease. 1990; 178(11):680-685. [PubMed: 2230754]

Gardner J, Oswald AJ. Money and Mental Well-being: A Longitudinal Study of Medium-sized Lottery Wins. Journal of Health Economics. 2007; 26(1):49-60. [PubMed: 16949692]

Gustman AL, Steinmeier TL, Tabatabai N. How Did the Recession of 2007-2009 Affect the Wealth and Retirement of the Near Retirement Age Population in the Health and Retirement Study? 2011 Oct. NBER Working Paper No. 17547.

Hudomiet P, Kezdi G, Willis RJ. Stock Market Crash and Expectations of American Households. Journal of Applied Econometrics. 2011; 26:393-415.

Kahneman D, Tversky A. Choices, Values, and Frames. American Psychologist. 1984; 39:341-350.

Kendler KS, Karkowski LM, Prescott CA. Causal Relationship between Stressful Life Events and the Onset of Major Depression. American Journal of Psychiatry. 1999; 156(6):837-841. [PubMed: 10360120]

Kim B, Ruhm CJ. Inheritances, Health, and Death. Health Economics. 2012; 21(2):127-144. [PubMed: 22223557]

Kuhn, Andreas. The Public Health Cost of Job Loss. Journal of Health Economics. 2009; 28(6):1099_ 1115. [PubMed: 19833399]

Lindahl M. Estimating the Effect of Income on Health and Mortality: Using Lottery Prizes as an Exogenous Source of Variation in Income. Journal of Human Resources. 2005; 40(1):144-168. 
Mazure, Carolyn M.; Bruce, Martha L.; Maciejewski, Paul K.; Jacobs, Selby C. Adverse Life Events and Cognitive-Personality Characteristics in the Prediction of Major Depression and Antidepressant Response. American Journal of Psychiatry. 2000; 157(6):896-903. [PubMed: 10831468]

McEwen BS. Stress, adaptation, and disease: Allostasis and Allostatic Load. Annals of the New York Academy of Sciences. 1998; 840(1):33-44. [PubMed: 9629234]

McFall BH. Crash and Wait? The Impact of the Great Recession on the Retirement Plans of Older Americans. American Economic Review: Papers and Proceedings. 2011; 101(3):40-44.

Meer J, Miller DL, Rosen H. Exploring the Health-Wealth Nexus. Journal of Health Economics. 2003; 22(5):713-720. [PubMed: 12946455]

Rabkin JG, Struening EL. Life Events, Stress, and Illness. Science. 1976; 194:1013-1020. [PubMed: 790570]

Radloff LS. The CES-D scale: A self-report depression scale for research in the general population. Applied Psychological Measurement. 1977; 1(3):385-401.

RAND HRS Data Version K. Produced by the RAND Center for the Study of Aging, with funding from the National Institute on Aging and the Social Security Administration. Santa Monica, CA: 2010.

Robert, C. Working paper. Harvard University; 2011 May. Wealth and Well-Being: Lessons from Indian Debt Relief.

Ruhm C. Are Recessions Good for Your Health? Quarterly Journal of Economics. 2000; 115(2):617650.

Schneiderman N, Ironson G, Siegel SD. Stress and Health:Psychological, behavioral, and biological determinants. Annual Review of Clinical Psychology. 2005; 1:607-628.

Schnittker J. When Mental Health Becomes Health: Age and the Shifting Meaning of Self-Rated Health. The Milbank Quarterly. 2005; 83:397-423. [PubMed: 16201998]

Shane RE, Woodruff PG, Dinno A, Covinsky KE, Walter LC. Prevalence and Risk Factors for Depressive Symptoms in Persons with Chronic Obstructive Pulmonary Disease. Journal of General Internal Medicine. 2008; 23(11):1757-1762. [PubMed: 18690488]

Simon, Naomi M. Treating Complicated Grief. JAMA, The Journal of American Medical Association. 2013; 310(4):416-423.

Smith JP. Unraveling the SES-Health Connection. Population and Development Review. 2004; 30:108-132.

Snyder SE, Evans WN. The Effect of Income on Mortality: Evidence from the Social Security Notch. Review of Economics and Statistics. 2006; 88(3):482-495.

Soto, M. Fact Sheet on Retirement Policy. Washington, DC: The Urban Institute; 2008. How Is the Financial Crisis Affecting Retirement Savings? December 3, 2008, Update

Steffick, DE. [accessed May, 23, 2013] Documentation of Affective Functioning Measures in the Health and Retirement Study. HRS/AHEAD Documentation Report, DR-005. 2000. Ann Arbor, MI: Survey Research Center, University of Michigan. Available at http://hrsonline.isr.umich.edu/ sitedocs/userg/dr-005.pdf,

Sullivan D, von Wachter T. Job Displacement and Mortality: An Analysis Using Administrative Data. The Quarterly Journal of Economics. 2009; 124(3):1265-1306.

Tefft N. Insights on Unemployment, Unemployment Insurance, and Mental Health. Journal of Health Economics. 2011; 30(2):258-264. [PubMed: 21349596]

Tefft N. Mental Health and Employment: The SAD Story. Economics \& Human Biology. 2012; 10(3): 242-255. [PubMed: 21907647]

Turvey CL, Wallace RB, Herzog R. A revised CES-D measure of depressive symptoms and a DSMbased measure of major depressive episodes in the elderly. International Psychogeriatrics. 1999; 11:139-148. [PubMed: 11475428]

Wooldridge, JM. Introductory Econometrics: A Modern Approach. 3rd. Mason, Ohio: Thomson South-Western; 2006. 


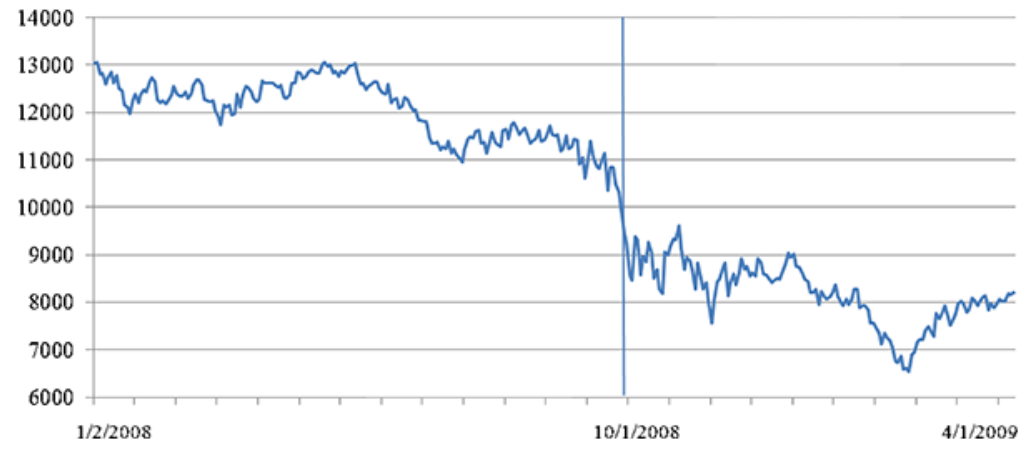

Figure 1. DJIA Daily Closing Value by 2008 HRS Fielding Date 


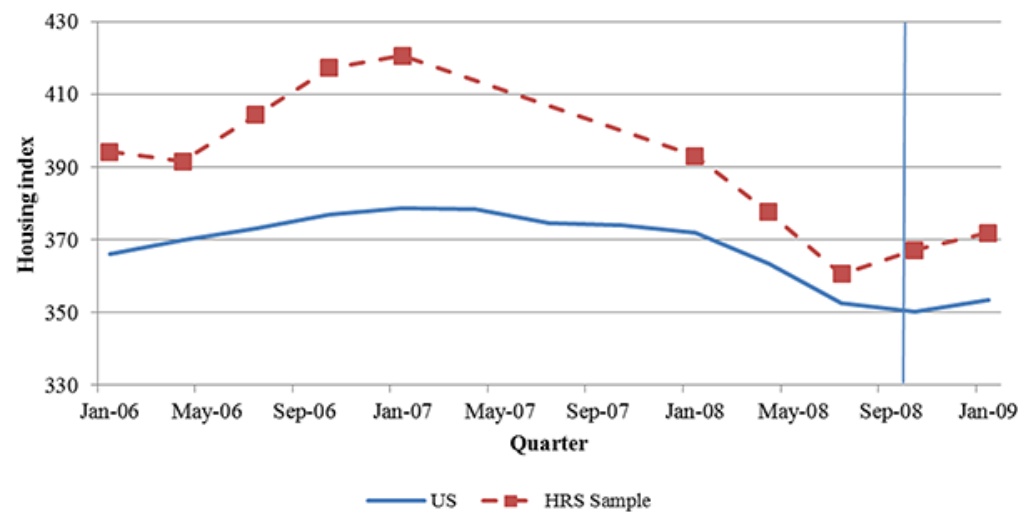

Figure 2A. FHFA House Price Index, All Transactions 


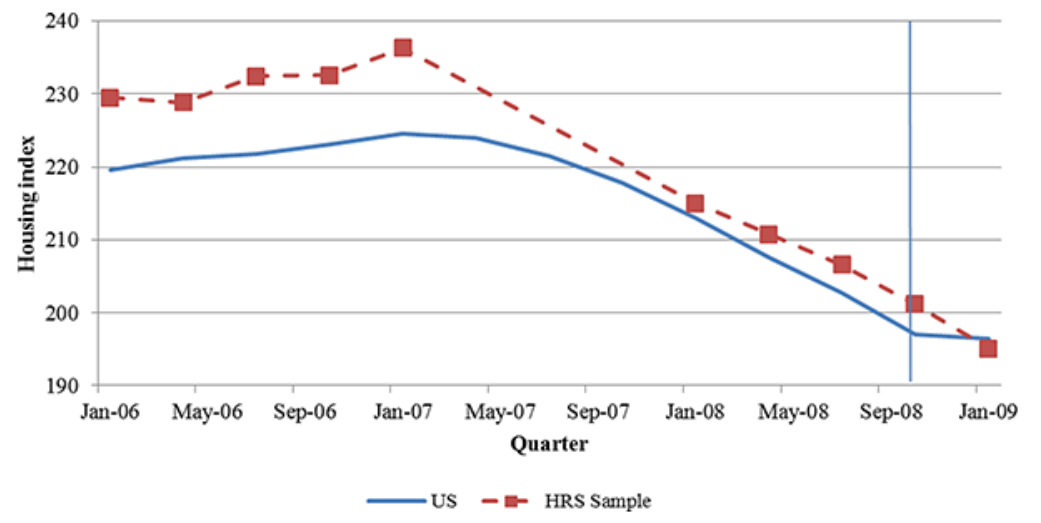

Figure 2B. FHFA House Price Index, Purchase Only, Adjusted 
Table 1

Descriptive Statistics for HRS Financial Respondents

\begin{tabular}{|c|c|c|c|c|}
\hline & \multicolumn{2}{|c|}{ Full Sample $(n=10,020)$} & \multicolumn{2}{|c|}{ Interviewed Post-Crash $(\mathrm{n}=\mathbf{8 1 5})$} \\
\hline & 2006 & 2008 & 2006 & 2008 \\
\hline Non-housing wealth (2008\$) & $344,491(1,912,915)$ & $292,861^{* *}(974,735)$ & $506,150(3,863,789)$ & $271,484 *(739,056)$ \\
\hline Financial wealth (2008 \$) & $147,471(1,115,278)$ & $133,699(546,440)$ & $140,331(634,355)$ & $113,830(394,535)$ \\
\hline CES-D & 1.54 & $1.48^{* *}$ & 1.65 & 1.62 \\
\hline CES-D $>=3$ & $23.2 \%$ & $21.7 \%^{* *}$ & $24.7 \%$ & $24.8 \%$ \\
\hline Rx for depression & $15.3 \%$ & $15.5 \%$ & $16.7 \%$ & $17.6 \%$ \\
\hline Feels depressed & $16.8 \%$ & $13.4 \%^{* * *}$ & $18.2 \%$ & $16.6 \%$ \\
\hline Self-Reported (SR) health (1=exc., 5=poor) & 2.84 & $2.94^{* * *}$ & 2.82 & $2.94^{* *}$ \\
\hline Excellent/very good SR health & $40.4 \%$ & $37.3 \%{ }^{* * * *}$ & $40.4 \%$ & $38.9 \%$ \\
\hline Age & $68.73(9.87)$ & $70.7^{* * *}(9.89)$ & $65.99(9.67)$ & $68.31^{* * *}(9.73)$ \\
\hline Female & 0.57 & 0.57 & 0.59 & 0.59 \\
\hline Black & 0.16 & 0.16 & 0.15 & 0.15 \\
\hline Hispanic & 0.09 & 0.09 & 0.10 & 0.10 \\
\hline Other race & 0.04 & 0.04 & 0.06 & 0.06 \\
\hline Less than high school & 0.21 & 0.21 & 0.21 & 0.21 \\
\hline Some college & 0.04 & 0.04 & 0.05 & 0.05 \\
\hline College degree & 0.12 & 0.12 & 0.12 & 0.12 \\
\hline Advanced degree & 0.10 & 0.10 & 0.10 & 0.10 \\
\hline Other education & 0.003 & 0.003 & 0.007 & 0.007 \\
\hline Education missing & 0.001 & 0.001 & 0.002 & 0.002 \\
\hline Never married & 0.04 & 0.05 & 0.05 & 0.05 \\
\hline Widowed & 0.28 & $0.30^{* *}$ & 0.24 & 0.27 \\
\hline Separated/divorced & 0.17 & 0.17 & 0.18 & 0.18 \\
\hline Marital status missing & 0 & $0.0004^{* *}$ & 0 & 0.002 \\
\hline Household income (in 2008 \$) & $60,080(184,595)$ & $62,102(610,002)$ & $70,812(120,803)$ & $75,348(272,277)$ \\
\hline No. persons in household & $2.00(1.14)$ & $1.98^{*}(1.12)$ & $2.13(1.28)$ & $2.09(1.34)$ \\
\hline Cognitive impairment category & $1.23(0.50)$ & $1.26^{* * *}(0.54)$ & $1.22(0.50)$ & $1.25(0.54)$ \\
\hline
\end{tabular}

Notes: The sample size in the column header row refers to the number of respondents with non-missing data on wealth. Missing data on mental health measures results in fewer observations. Statistically significant differences between 2008 and 2006 values are indicated by $* * *$ for 0.01 level, ** for 0.05 level, and * for 0.10 level. 


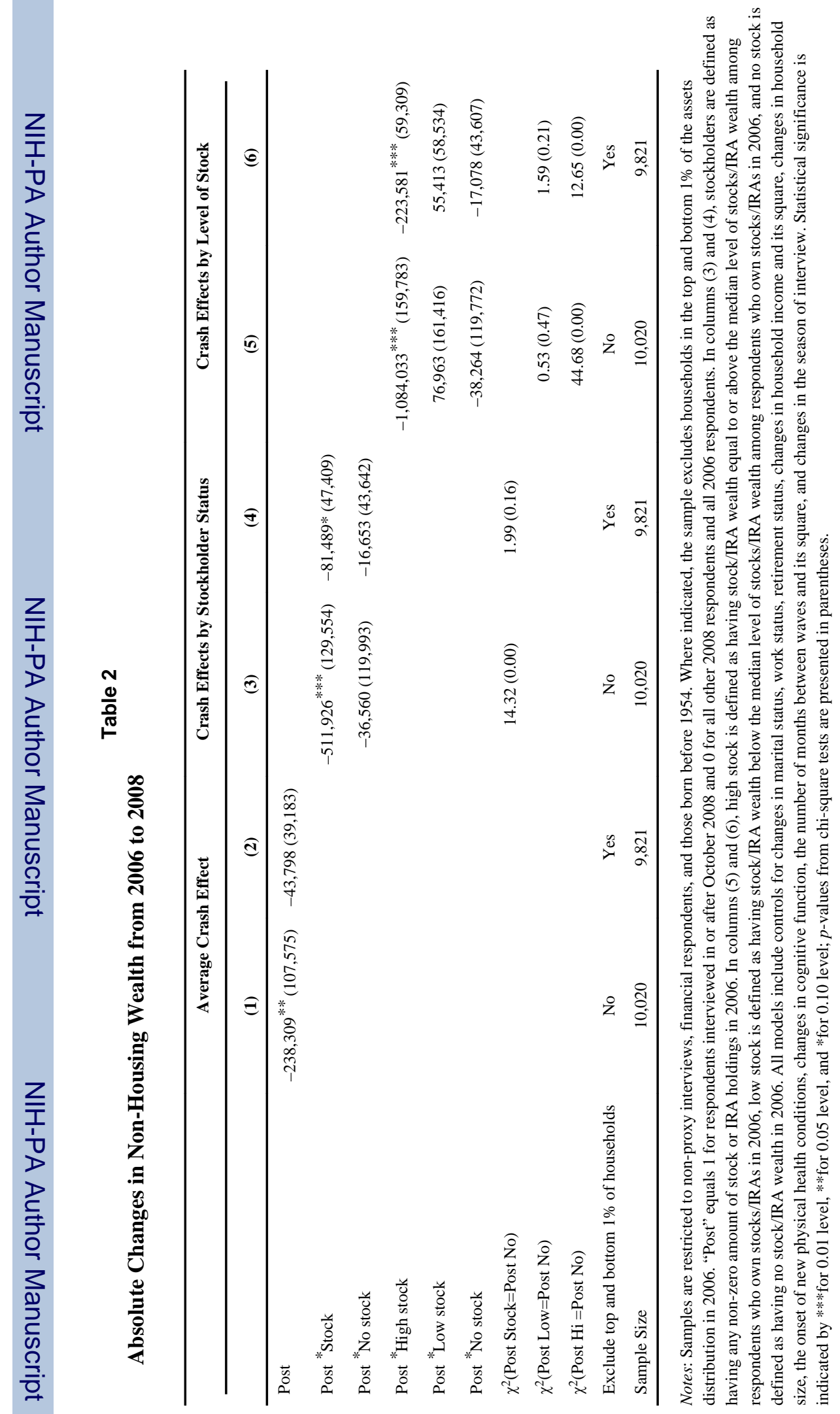

$J$ Health Econ. Author manuscript; available in PMC 2014 December 01. 


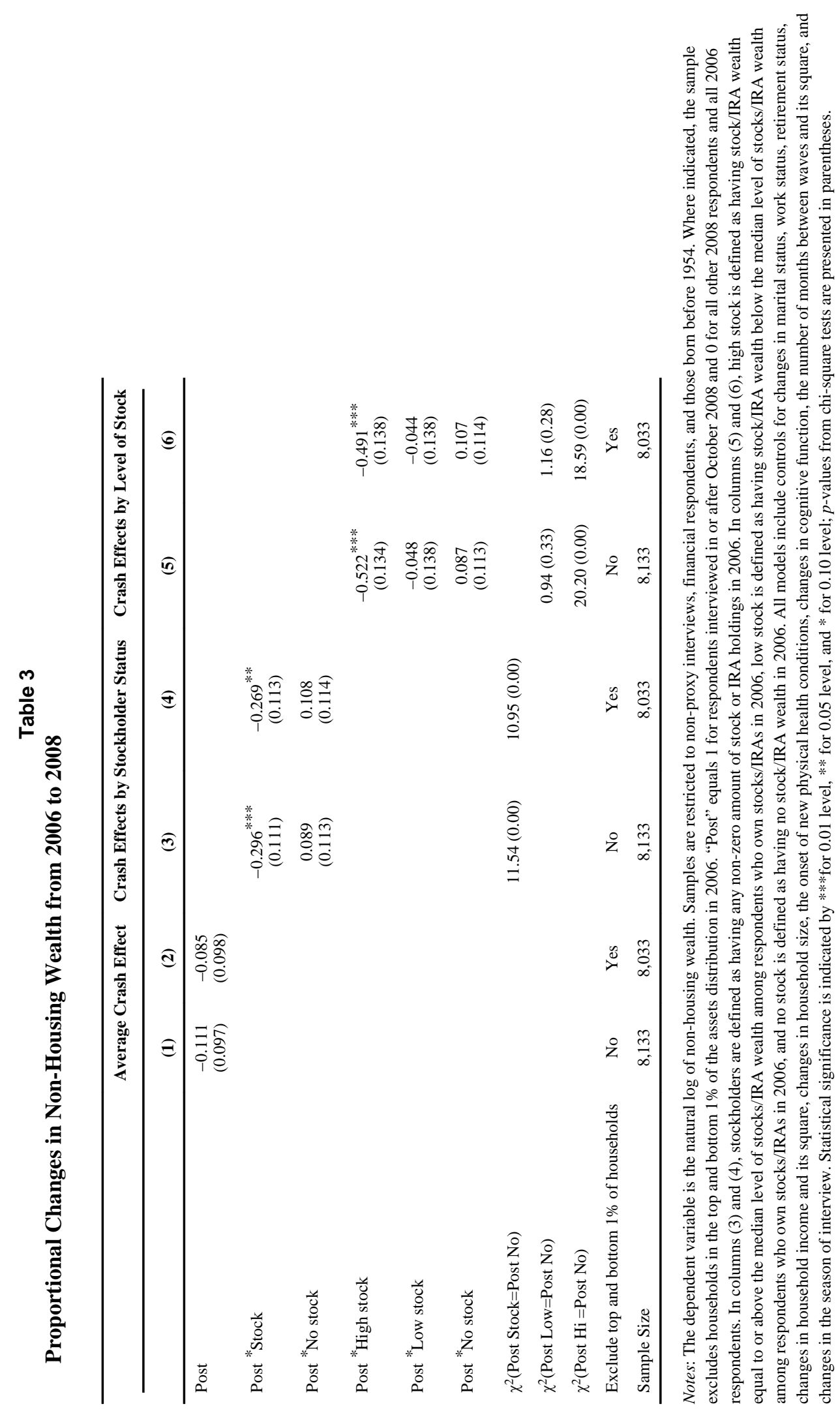

J Health Econ. Author manuscript; available in PMC 2014 December 01. 


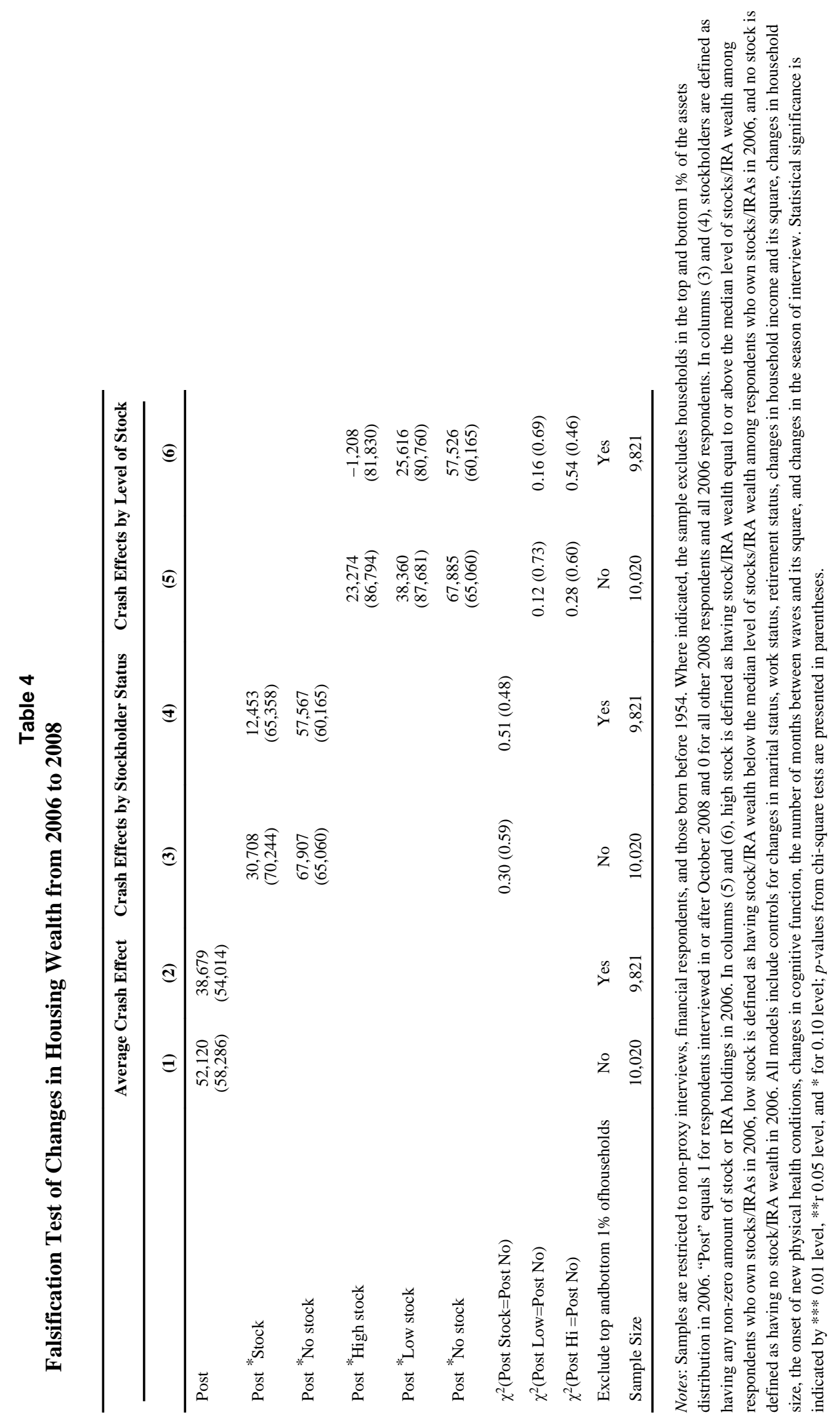

$J$ Health Econ. Author manuscript; available in PMC 2014 December 01. 


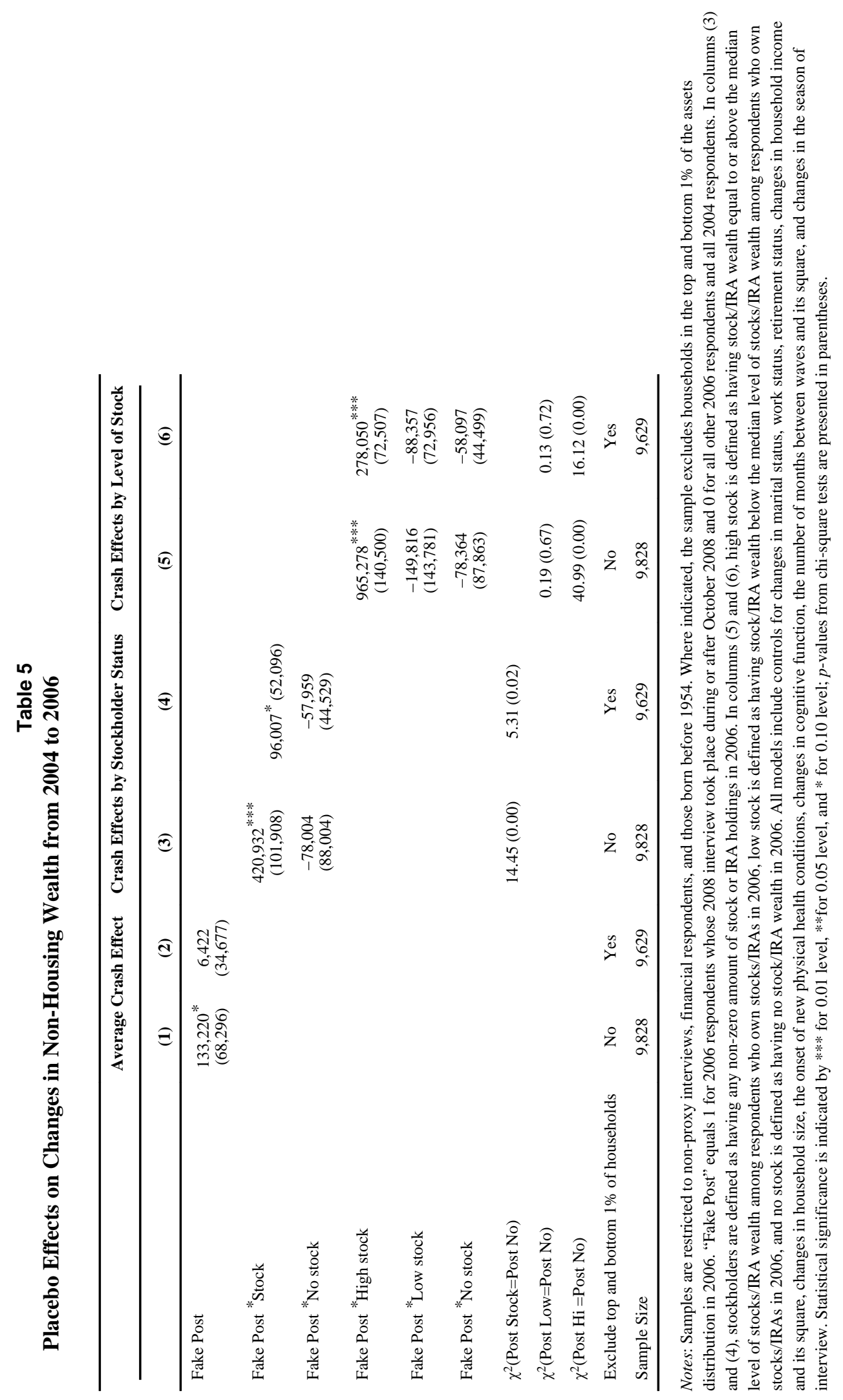

J Health Econ. Author manuscript; available in PMC 2014 December 01. 


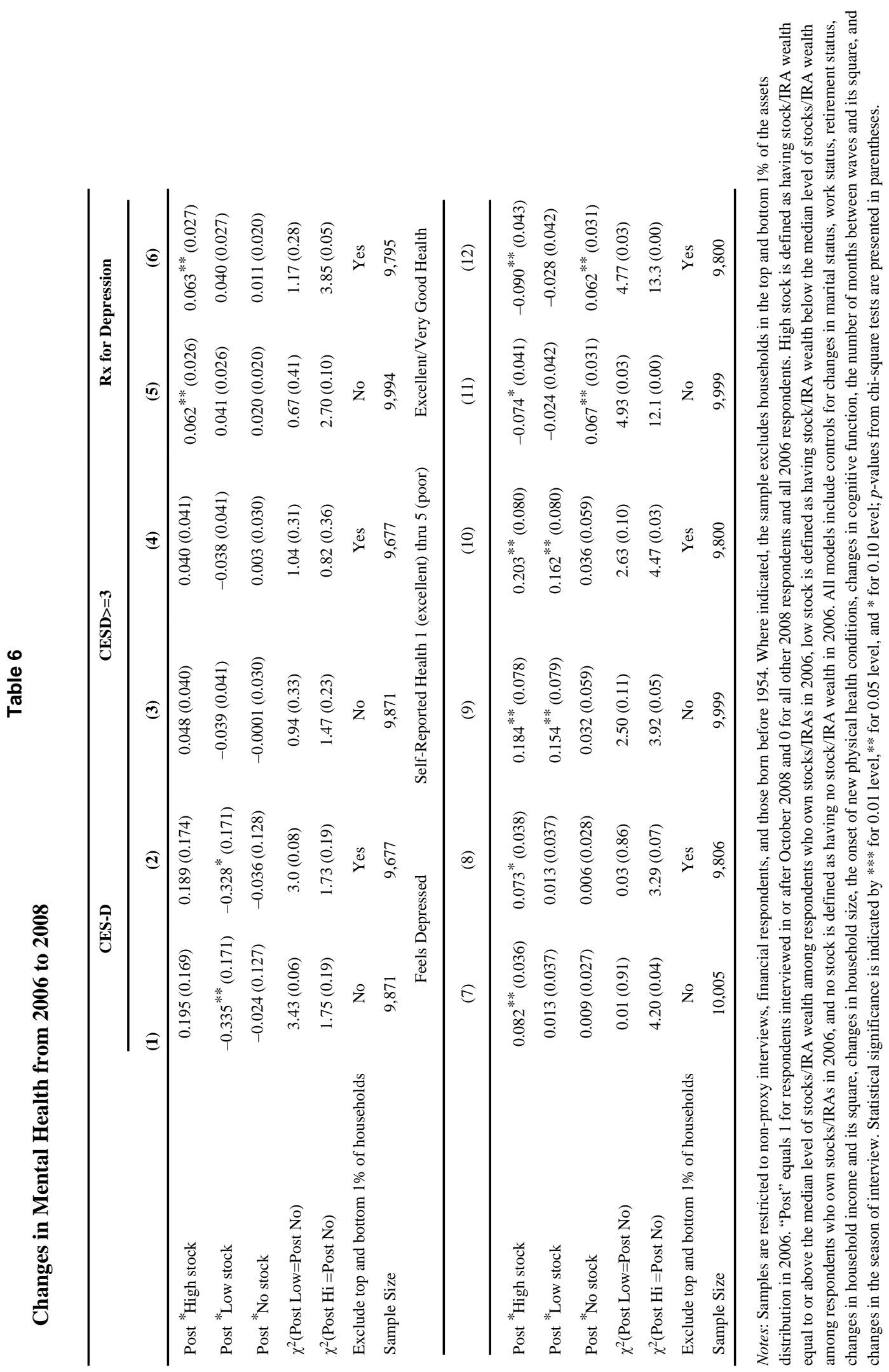




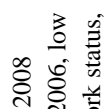

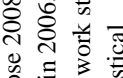

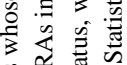

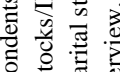

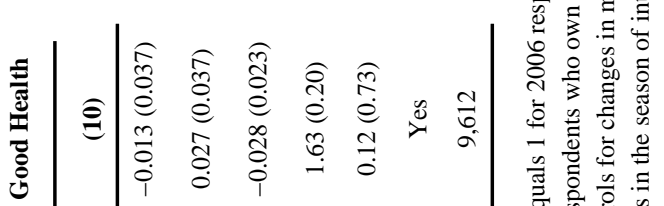

a

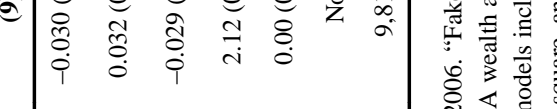

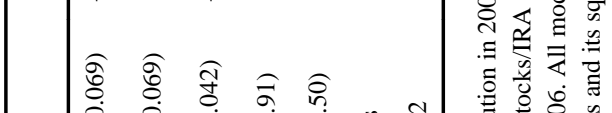

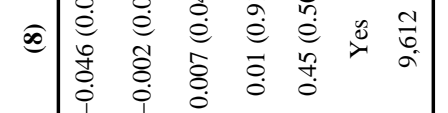

要客

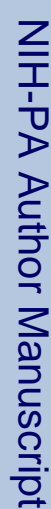

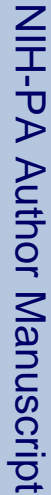

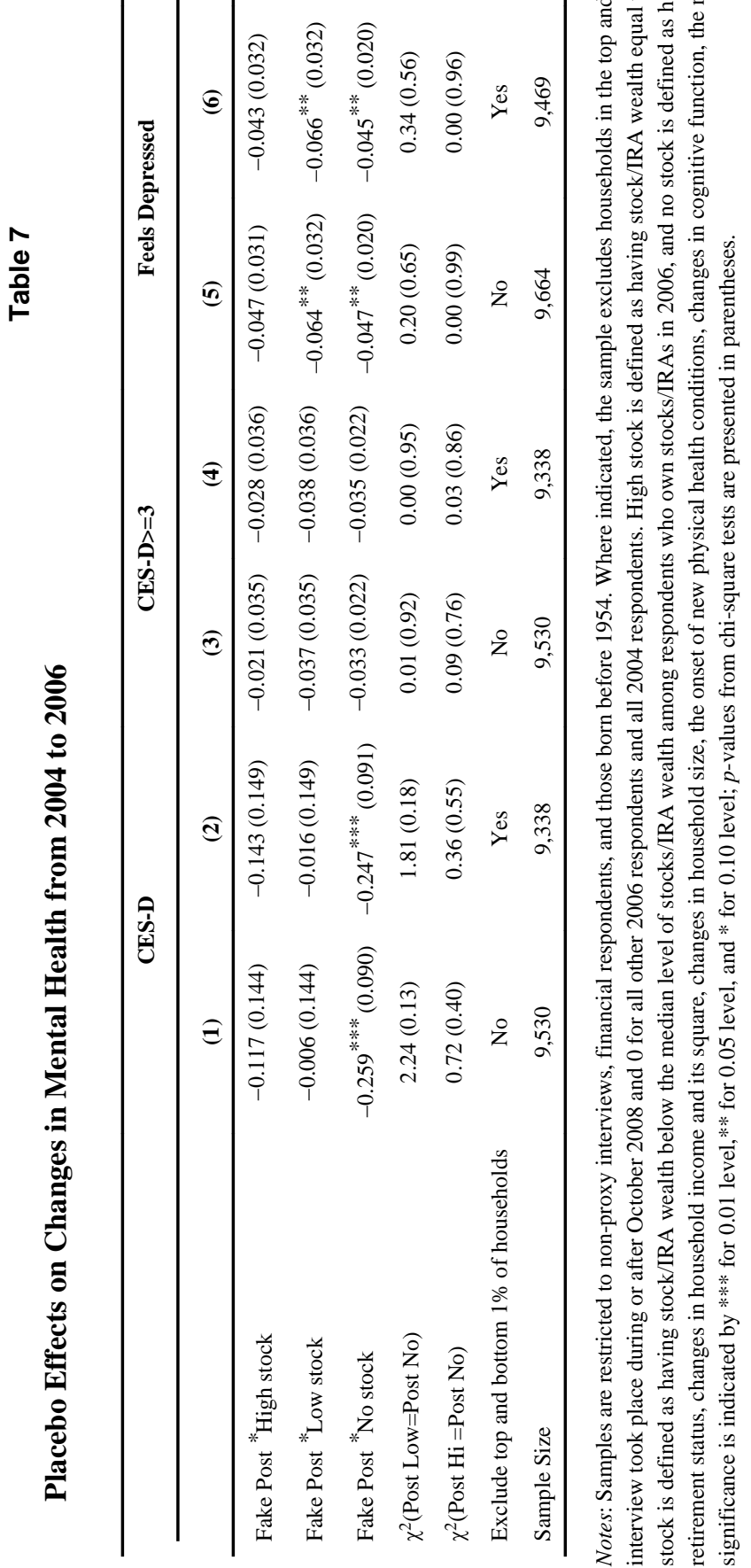

